УДК 340.1

Р. Р. Габрилян

\title{
К ВОПРОСУ ОБ ОБЫЧНО-ПРАВОВЫХ СПОСОБАХ РАЗРЕШЕНИЯ СПОРОВ И КОНФЛИКТОВ (НА ПРИМЕРЕ ЮЖНО-ТИХООКЕАНСКОГО РЕГИОНА)
}

Настоящая статья посвящена способам разрешения правовых конфликтов в обычном праве народов, проживающих в Южно-Тихоокеанском регионе, анализируются проблемы использования достижений обычного права в сфере разрешения правовых конфликтов в различных правовых системах современных государств. С помощью ряда методов исследования, таких как исторический и сравнительно-правовой, выделяются обстоятельства, обусловившие формирование способов разрешения конфликтов в обычном праве региона, рассматриваемого в настоящей статье.

В статье раскрывается роль как глав общин, так и рядовых членов общин в разрешении правовых конфликтов. Делается вывод о положительном влиянии обычного права на позитивное право, в частности, в вопросе выработки таких нехарактерных последнему способов разрешения правовых конфликтов, как примирительные процедуры. Приводятся доводы о необходимости дальнейшего исследования способов разрешения конфликтов в соответствии с обычным правом народов Южно-Тихоокеанского региона, так как они способствуют не только разрешению конфликтов у народов, применяющих обычное право для разрешения подобных конфликтов, но и могут обогатить другие правовые системы.

Научная новизна работы состоит в исследовании путей совершенствования современных способов разрешения правовых конфликтов, опирающихся на обычно-правовые нормы.

Ключевые слова: обычное право, обычай, суд конфликт, правовой спор, примирительные процедуры, медиация, правовой плюрализм, Океания, Южно-Тихоокеанский регион

R. R. Gabrilyan

\section{ON CUSTOMARY LAW RESOLUTION OF DISPUTES AND CONFLICTS (BY THE EXAMPLE OF THE SOUTH PACIFIC REGION)}

The paper covers the ways of resolving legal conflicts in the customary law of peoples living in the South Pacific region. The problems of using the achievements of customary law in the sphere of legal disputes resolution in various legal systems of modern states are analysed. Through the instrumentality of a number of research methods, such as a historical method and a comparative legal method, the circumstances that determine the formation of manners for conflicts resolution in the customary law of the region are highlighted in the article.

The paper reveals the role of both heads of communities and ordinary members of communities in legal conflicts resolution. A conclusion is made about the positive effect of customary law on positive law, in particular, on the issue

।

Системой историко-теоретических наук под правовым обычаем признается устоявшееся обязательное правило поведения, сложившееся в результате длительного повторения. Несмотря на то, что право является одним из важнейших признаков государства, обычное право, являясь древнейшим источником права, возникает у многих народов мира задолго до появления государства. При этом рядом учёных высказывается мнение о санкционировании обычаев государством. Может ли обычное право продолжать именоваться обычным после его санкционирования госу- of conciliatory procedures that are unusual to the positive law manners of resolving legal conflicts. It is logically argued that further research on ways of conflicts resolution in accordance with the customary law of the peoples of the South Pacific region is needed, since they contribute not only to resolving conflicts among peoples who apply customary law to resolve such conflicts, but also enrich other legal systems.

The scientific originality of the research lies in studying the ways of improving modern methods of legal conflicts resolution, based on the ordinary legal norms.

Key words: customary law, custom, court, conflict, legal dispute, conciliation, mediation, legal pluralism, Oceania, South Pacific.

дарством? Считаем, что утвердительно на данный вопрос ответить не представляется верным, так как, обретя позитивную форму, обычай приобретает иную конфигурацию, противоречащую его сущности и определению.

В современном мире обычное право зачастую не рассматривается в качестве источника права, либо отмечается его устаревший статус, в особенности это касается стран континентальной правовой системы. В странах англо-саксонской правовой системы, а также в религиозных правовых системах, правовой обычай традиционно признаётся одним из источников права. Тем 
не менее, в последние десятилетия отмечается рост интереса к обычному праву среди исследователей-правоведов. В ряду причин подобного интереса выделим развитие такой междисциплинарной науки как юридическая антропология, установление приоритета прав человека в правовой политике государств мира, и, конечно, популяризация идеи правового плюрализма

Идея правового плюрализма, несмотря на её современность, имеет глубокие корни, уходящие в древность. Так, известный американский юрист Б. 3. Таманаха отмечает, что после распада Римской империи на территории, ранее ей принадлежавшей и простиравшейся с Северной Африки до Британии, проживали различные народы - от германских племён, норманнов, гуннов до пришлых арабов. Долгое время местные неписаные обычаи, нормы обычно-правовых кодификаций римское право, феодальное право, городское право, торговое право и законы соприкасались с обычаями и законами завоевателей, а также с каноническим правом [14]. Естественно, подобное положение нередко приводило к правовым конфликтам, однако продолжительная европейская история свидетельствует о том, что данное сосуществование жизнеспособно

У идеи правового плюрализма имеются как сторонники, так и противники. Даже не придерживаясь точки зрения первого лагеря, нельзя не заметить положительных качеств правового плюрализма, как в ретроспективе, так и в современном мире, и, более того, в перспективе. Так после крушения колониальной системы в середине прошлого столетия только благодаря реализации идеи правового плюрализма во многих бывших колониях западных империй от Африки до Азии и Океании удалось избежать конфликтов либо относительно легко их преодолеть. Безусловно, до того момента само насаждение права, долгое время развивавшегося в условиях капиталистических отношений, не могло проходить без затруднений в территориях, развивавшихся на протяжении многих веков в качестве сельскохозяйственных и животноводческих общин, управлявшихся вождями и живших в соответствии с обычным правом [11]

Исходя из указанных в качестве положительных сторон правового плюрализма, можно сделать вывод о месте и значении обычного права в современных правовых системах. Как уже отмечалось, в англо-саксонской правовой системе обычное право признается источником права, что связано с особенностью формирования самой правовой системы, базой для которой явились местные обычаи и судебная практика. Естественно, обычаи не являются основным источником права, более того, не все обычаи могут быть признаны частью правовой системы, а лишь те, которые существуют со времени коронации короля Ричарда I Львиное Сердце (3 сентября 1189 г.) так как ещё в 1275 г. Первым Вестминстерским Статутом Эдуарда I предыдущий период истории английского государства был определён как «не- запамятные времена», что было подтверждено Актом о давности 1832 г.» [5].

Несмотря на серьёзные отличия в иерархии источников права в некоторых государствах романо-германской правовой системы обычное право также может быть названо одним из источников права.

В отдельных странах смешанных правовых систем обычное право также признается источником права. Так, обычаи, наряду с религиозным и общим правом, играют важную роль в Индии.

Сложно переоценить значимость обычаев в правовых системах многих африканских и островных тихоокеанских государств. В большинстве их них обычай закрепляется в качестве источника права на законодательном уровне, чаще всего в конституциях. Например, в Конституции Самоа говорится о том, что независимое государство создаётся на принципах христианства и самоанских обычаев и традиций, а сами обычаи в ст. 111 перечисляются наряду с другими источниками права [6].

Безусловно, нельзя не упомянуть и о такой важной сфере как международное право, в котором обычай продолжает оставаться особенным источником права, признание которого можно обнаружить в Статуте Международного суда $\mathrm{OOH}$ (п.b. ст.38), где международный обычай определяется как «доказательство всеобщей практики, признанной в качестве правовой нормы» [13] Важно помнить, что нарушение международно-правового обычая признаётся правонарушением, в отличие от международного обыкновения.

Таким образом, считаем, что признавать обычное право в современном мире анахронизмом преждевременно. Правовой обычай в ряде стран играет важную роль, способствуя как реализации прав и свобод человека, так и выступая в качестве сглаживающего конфликты инструмента.

$$
\text { II }
$$

Любой правовой спор воспроизводит в кризисных обстоятельствах обширный круг значимых характерных особенностей процесса взаимодействия субъектов правоотношений.

Особенность права как важнейшего аппарата регулирования общественных отношений состоит в возможности и способности нивелировать возникающие споры и конфликты, а также превентивно воздействовать на общество с целью недопущения возникновения таких ситуаций в будущем.

Немаловажным является вопрос о понятиях «правовой спор» и «правовой конфликт». Как справедливо отмечает А. Б. Зеленцов, учёными-правоведами используется два подхода к определению термина «правовой спор». Так, в первом подходе «правовой спор» представляет собой объединение различных видов спора, таких, как спор о праве субъективном, спор о праве объективном, спор о законном интересе, спор о юридическом факте, спор об ответственности и т.д. Синонимичным данному понятию является 
понятие «спор о праве». В более узком понимании «правовой спор» представляет собой только спор о субъективном праве. Исследователями приводятся такие трактовки правового спора как «сопротивление, помеху осуществлению права», «противоречие», «юридизированный фактический конфликт», «разногласия» [2]. Исследуя различные позиции относительно понимания категории «правовой спор» можно обнаружить, что все они отсылают к конфликтной природе отдельного правового отношения.

Наиболее полным является приведённое В. Н. Кудрявцевым определение термина «правовой (юридический) конфликт», как «любой конфоликт, в котором спор так или иначе связан с правовыми отношениями сторон (их юридически значимыми действиями или состояниями) и, следовательно, субъекты, либо мотивация их поведения, либо объект конфликта обладает правовыми признаками, а конфлликт влечёт юридические последствия» [4].

Исследователи Касьянов В. В. и Нечипуренко В. Н. выделяют два вида конфликтов - обладающие юридическим характером и не обладающие таковым, но включающие правовой элемент. Правовой конфликт возникает между социальными субъектами по причине различия их правовых интересов и образующийся вокруг их правового статуса. При этом, отмечается, что правовой конфликт может развиваться из неправового, например, при невозможности разрешения конфликта самостоятельно, без обращения в соответствующие уполномоченные структуры. Говоря о неправовых конфликтах, влекущих за собой возникновение правового конфликта, авторы справедливо указывают на вторичность последнего, который вытекает из первичных конфликтов - социального, семейного и так далее. При этом можно вывести формулу конфликта, который состоит из конфликтной ситуации, субъектов и непосредственно инцидента [3].

В современной юриспруденции выделяют два основных порядка разрешения возникающих правовых конфликтов: судебный и внесудебный.

Судебный способ разрешения правовых конфликтов является наиболее распространённым во всём мире, вне зависимости от принадлежности правовой системы того или иного государства к конкретной правовой семье. Данный способ является наиболее затратным, так как требует участия широкого круга лиц-представителей государственной власти, более того, данный способ может быть назван способом разрешения конфликта, но не всегда способом завершения конфликта, так как в данном случае одна сторона будет продолжать считать себя пострадавшей.

Внесудебный порядок разрешения конфликтов представляет собой упрощённый способ, не требующий вовлечения в процедуру судебных органов власти. В последнее время всё большую популярность получают виды внесудебного порядка разрешения правовых конфрликтов, названные альтернативными (примирительными).
Причём если судебный порядок достаточно хорошо изучен и распространён, то, например, такой альтернативный вид разрешения конфликтов, как медиация, в отличие от ряда западных стран, в России только делает первые шаги.

Обычно-правовые способы разрешения конфоликтов складывались на протяжении многих веков. Обычное право, оставаясь практически неизменным, давало возможности вырабатывать наиболее уникальные и действенные методы для разрешения конфликтов, без необходимости прибегать к способам, санкционированным государством и позитивным правом. Обычно-правовые способы, в отличие от привычных правовых способов разрешения конфликтов, имеют главной целью не установление юридической справедливости, а зиждутся на восстановлении баланса в обществе, который конкретный конфликт может нарушить, а также для создания предпосылок, способствующих невозможности повторения подобных конфликтов в будущем.

Особую роль в обычно-правовых способах разрешения конфрликтов играет авторитет старейшин, вождей общин. Кроме того, в подавляющем числе случаев в разрешение конфрликтов по обычному праву вовлечён широкий круг участников-членов общины. Несмотря на то, что данные способы носят неписаный характер, исполнение вынесенных решений никоим образом не страдает от этого, так как в числе факторов, обеспечивающих их реализацию, не только авторитет старейшин общины, но и авторитет самой общины, а также устоявшихся правил поведения, передаваемых из поколения в поколение.

III

В отличие от стран с англо-саксонской и романо-германской правовыми системами, в странах, где традиции и обычаи имеют важное значение в правовой сфере, ситуация с разрешением споров имеет несколько иной характер. Среди таких стран особое место занимают государства Океании, во многих из которых обычаи закреплены в качестве одного из источников права, в том числе на уровне конституций.

Важнейшим фактором, определяющим успешное разрешение споров на основе обычаев и традиций в государствах и территориях Океании, является авторитет вождей. Властные полномочия передаются в различных местностях по-разному, однако, обратив внимание на полинезийские народы можно обнаружить, что вождизм здесь носит наследственный характер, тогда как у меланезийских народов передача по наследству должности вождя не принята, хоть и можно проследить определённые черты наследственной передачи власти и у некоторых меланезийцев. Как отмечают учёные, в частности Гай Поулз, власть вождей зачастую получает и конституционную защиту. Например, в ряде стран вожди вовлечены в законотворческий процесс (Самоа, Американское Самоа, Тонга, Фиджи, Маршалловы Острова и Федеративные Штаты Микронезии), 
имеют совещательные функции (Острова Кука и Вануату) или даже получают судебные полномочия (Самоа, Вануату и Соломоновы Острова). Более того, в Королевстве Тонга вся система органов государственной власти выстроена в целях удовлетворения функций традиционной власти вождей [12]. Гай Поулз также указывает, что в Вануату принятие любых законопроектов, касающихся разрешения земельных споров должно в обязательном порядке согласовываться с вождями [12]

Власть вождей на островах Океании представляет собой многоуровневую систему. Так, например, в Вануату на самом низшем уровне находятся вожди определённых деревень, над ними может находиться совет вождей нескольких поселений, и, наконец, вожди на самом высоком национальном уровне. При необходимости разрешить спор дело рассматривается сначала на уровне деревень, причём вожди стараются сделать путём достижения согласия в семье или семьях, где возникла конфрликтная ситуация и только затем в случае неудачи, конфлликтом будут заниматься вышестоящие обычно-правовые органы. При этом следует помнить, что ситуация отличается не только от одного тихоокеанского островного государства к другому, но и от одного острова к другому в рамках одного государства [8].

Важным вопросом является создание обычно-правовых судов в странах и территориях Океании. Однако, как пишет Дженнифер Коррин Кеа, несмотря на то, что данные суды могут руководствоваться обычно-правовыми нормами, они не могут являться обычно-правовыми полностью, т.к. они учреждаются в соответствии с принципом состязательности и ограничиваются соответствующими нормами процессуального права [7].

Однако решения, вынесенные на основе обычного права вне таких судов, могут быть поставлены вне закона и оспорены в судах, признаваемых государством.

Как было отмечено в докладе Австралийского Национального консультативного совета по альтернативным методам разрешения споров эффрективные способы разрешения споров и конфликтов помогают коренным народам получить доступ к различным ссрерам правосудия и решить социальные, экономические и культурные задачи. Подобные способы обладают потенциалом в уменьшении уровня насилия в общинах коренных народов сокращения количества контактов представителей коренных с системой уголовного правосудия, способствовании исцелению повреждённых связей между коренными и улучшении управления и принятия решений общинами. При этом потенциал до сих пор полностью не реализован [9].

Что же собой представляют подобные способы разрешения споров и конфликтов?

Характерной чертой обычно-правового решения конфликтов в Океании является попытка исчерпать конфоликт, не прибегая при этом к государственным органам. Авторитет вождей и представителей старшего поколения чрезвычайно высок у народов Океании. Таким же авторитетом обладают решения данных лиц, как и обычное право в целом. Ведь зачастую, нарушив норму обычного права, коренные жители Океании, по сути, теряют связь со своей общиной.

Исследуя процесс решения споров на основе обычаев можно заметить, что процедура не так уж и устарела, более того, современные государства, все чаще делающие упор на альтернативные способы решения споров, многое заимствуют именно у обычно-правовых систем, для которых медиация и примирительные процедуры являются основными.

Ярким примером является Новая Зеландия государство с англосаксонской правовой системой, на которое особое влияние оказывают решения Трибунала Вайтанги, учреждённого для разрешения споров с представителями доевропейского населения - маори, и само обычное право народа маори. Всего чуть более двух десятилетий назад в Новой Зеландии была осуществлена попытка объединить лучший инструментарий решения конфликтов как со стороны общего права, так и обычного права маори. Ювенальная юстиция не оправдывала всех возложенных на неё надежд и правительство бывшей британской колонии решилось на эксперимент, а именно введение в практику нового института - реституционного правосудия, или как его ещё называют восстановительного правосудия. Принятый в 1989 г. Акт «О детях, несовершеннолетних и их семьях》 стал ответом на царившее насилие в стране, прежде всего, в среде маори. Данный институт был выбран в связи с тем, что был знаком народу маори, Т.к. ключевыми моментами реституционного правосудия стали примирение, паритет, взаимоуважение и сотрудничество, а также «фанау» - имеющий много значений термин, в первую очередь означающий сложную семью или общину.

При разрешении конфрликтов с применением реституционного правосудия главный упор делается не на наказание виновного лица и лишение его свободы либо ограждении от общества, а на возмещении ущерба потерпевшей стороне. Поэтому данный, вышедший из обычного права институт и называют восстановительным. Система показала себя настолько успешно, что постепенно современные развитые страны мира решились на внедрение опыта Новой Зеландии в своих правовых системах.

Обычно-правовые конфликты, решаемые в странах Океании можно разделить на две категории - конфликты в рамках одной общины и конфликты между различными общинами. Первая категория правовых конфликтов решается внутри общины, чаще всего на общем собрании поселения (деревни), при участии старейшин, либо более узкой группы.

Боязнь возмездия со стороны высших сил и презрение со стороны жителей общины, многие из которых состоят в родстве с нарушителем обычно-правовых норм, помогают восстановить нарушенную норму и вернуть статус-кво. 
Описывая процедуру разрешения конфликта по обычному праву народов Вануату, Миранда Форсайт приводит такие факты [8]: процесс начинается с оплаты небольшой суммы вождю, что можно сравнить со своеобразной пошлиной. На следующем этапе вождь созывает собрание, либо, как это происходит в некоторых общинах, вождь с помощниками пытается определить, можно ли разрешить конфликт, не прибегая к созыву собрания, проведя беседы со сторонами. Собрания проходят в особых для каждой деревни сооружениях, называемых накамал. В некоторых местностях, считается необходимым даже приглашать на слушания жителей соседних деревень, таким образом, поддерживается необходимый баланс. При этом жители и данной общины не обязательно должны находиться в одном помещении, например, женщины и молодёжь зачастую находятся за пределами накамала. Однако они в большинстве регионов могут выступать на слушаниях, которые выделяются своим состязательным характером. Завершается процесс либо выступлением вождя, выносящего решение, либо самих сторон, которые подталкиваются к определённому решению, главной целью которого является установление порядка и мира. Примечательно, что в некоторых деревнях вожди после оглашения решения, испрашивают мнения собравшихся, устраивает ли их оно, и, в случае отрицательного ответа, продолжаются попытки прийти к устраивающему всех решению. После процесса проводится особая примирительная процедура, например, совместное принятие пищи и с употреблением традиционного напитка «кава».

Конфликты между общинами решаются посредством особых церемоний, общих для представителей (преимущественно, старейшин и вождей) разных общин, а также советов вождей - специально созданных органов, созданных в некоторых государствах. C распространением христианства на островах Океании большую примиряющую роль стали играть священнослужители [10].

\section{IV}

Считаем крайне важным отметить, что в каждом государстве, в особенности, полиэтничном, одной из важнейших целей государственной власти должно быть способствование социокультурным интересам населения, одним из которых вы- ступает обычное право. Следует признать, что в современном мире проблема выживания многих правовых обычаев действительно является актуальной. Нельзя и не согласиться с мнением, что некоторые из них, действительно, архаические и несовместимы с бурно развивающимся человечеством.

Действительно, сосуществование обычного права и западных правовых систем - проблема крайне сложная, при этом, именно благодаря подобному сосуществованию и взаимодействию, удаётся найти решение многих проблем в различных сфрерах правового регулирования. Сохранение уникальных традиций и обычаев не должно являться самоцелью, неизмеримо важнее направить данные обычаи в русло современных тенденций развития правовых институтов, в частности прав и свобод человека [1]

Тем не менее, за века и тысячелетия своего формирования, обычное право, без сомнения, доказало способность к выживанию, адаптации, а также возможность оказать положительное влияние на позитивное право. Таким институтом по праву можно считать рассматривавшийся в настоящей статье институт разрешения правовых конфликтов. Ярчайшим примером однозначно могут служить примирительные, медиационные процедуры, которые получают распространение во многих странах мира.

В странах Океании актуальным является вопрос создания обычно-правовых судов, при этом решения, вынесенные на основе обычного права вне таких судов, могут быть поставлены вне закона и оспорены в судах, признаваемых государством.

Обычно-правовые способы, в отличие от привычных правовых способов разрешения конфликтов, имеют главной целью не установление юридической справедливости, а зиждутся на восстановлении баланса в обществе, который конкретный конфликт может нарушить, а также для создания предпосылок, способствующих невозможности повторения подобных конфликтов в будущем. Кроме того, особую роль в обычно-правовых способах разрешения конфрликтов играет авторитет старейшин, вождей общин. В подавляющем числе случаев в разрешение конфрликтов по обычному праву вовлечён широкий круг участников-членов общины.

\section{Литература / References}

1. Габрилян Р. Р. Проблемы обычно-правового регулирования семейно-брачных отношений в государствах и территориях Океании в колониальный и постколониальный периоды // Проблемы и перспективы развития современной юриспруденции. Сборник научных трудов по итогам международной научно-практической конференции, Воронеж: Инновационный центр развития образования и науки, 2014. С. 19-21

Gabrilyan R. R. Problemy obychno-pravovogo regulirovaniya semeino-brachnykh otnosheniy v gosudarstvakh i territoriyakh Okeanii v kolonialnyi i postkolonialnyi periody (Problems of Customary Regulation of Family and Marriage Relations in the States and Territories of Oceania in the Colonial and Postcolonial Periods) // Problemy i perspektivy razvitiya sovremennoi yurisprudentsii/Sbornik nauchnykh trudov po itogam mezhdunarodnoi nauchno-prakticheskoi konferentsii. Voronezh, 2014 P. 19-21. (In Russian).

2. Зеленцов А. Б. Теоретические основы правового спора: дисс. ... докт. юрид. наук. М., 2005. 435 с

Zelentsov A. B. Teoreticheskie osnovy pravovogo spora (Theoretical Foundations of Legal Dispute): thesis. Moscow, 2005 435 p. (In Russian). 
3. Касьянов В. В., Нечипуренко В. Н. Социология права: учебник для бакалавриата и магистратуры. М.: Юрайт, 2016. $380 \mathrm{c}$.

Kasyanov V. V., Nechipurenko V. N. Sotsiologiya prava (Sociology of Law): textbook. Moscow: Yurait, 2016. 380 p. (In Russian).

4. Юридический конфликт: сферы и механизмы, М.: РАН, 1994. 172 с

Yuridicheskiy konflikt: sfery i mekhanizmy. Moscow: RAS publ., 1994. 172 p. (In Russian)

5. Bederman D. J. Custom as a Source of Law. Cambridge: Cambridge University Press, 2010.

6. Constitution of the Independent State of Samoa 1960. URL: www.paclii.org/ws/legis/consol_act_2008/cotisos1960438.

(Дата обращения: 25.05.2018).

7. Corrin Care J., Wisdom \& worthy customs: Customary law in the South Pacific // Reform. 2002. 80. P.31-36.

8. Forsyth M. A Bird that Flies with Two Wings: Kastom and state justice systems in Vanuatu. Canberra: ANU Press, 2013

9. Indigenous Dispute Resolution and ConflictManagement. URL:www.ag.gov.au/LegalSystem/AlternateDisputeResolution/ Documents/NADRAC\%20Publications/Indigenous\%20Dispute\%20Resolution\%20and\%20Conflict\%20Management.PDF. (Accessed: 01.06.2018).

10. Klyukovskaya I. N., Demchenko T. I., Gabrilyan R. R., Kardanova A. K., Popova L. A. Legal conflicts resolution in customary law of peoples of the world // Man in India. 2018. 97(22). P. 243-258.

11. Merry S. E. Legal pluralism // Law \& society review. 1988. No. 22(5). P. 869-896.

12. Powles G. Traditional Authority in the Contemporary Pacific: Conflict and Compromise in Legal and Political Systems in "9th Commonwealth Law Conference" Conference Papers, Auckland: Commerce Clearing House NZ Ltd, 1990b. P. 571-579.

13. Statute of the International Court of Justice. URL: www.icj-cij.org/homepage/ru/icjstatute.php. (Accessed: 25.05.2018)

14. Tamanaha B.Z. Understanding legal pluralism: past to present, local to global// Sydney L. Rev. 2008. No. 30. P. 375. 